It dibehnrge from the left ear had ceased, and the hearing was considerably improved; but the busxing and ticking remained. I was still unable to procure a view of the right membrana tympani.

July 17th. He continued to improve: the hearing was considerably better, and the discharge had ceased in both ears; the buzzing was fainter, but the ticking remained. He slept, and felt well. The day being bright, I obtained an excellent view of both membrano tympani; that of the right was entirely altered in colour and appearance. Instead of being smooth, translucent, and shining, its surface was irregular, highly vascular, and had exactly the appearance of a granulating ulcer. The left membrane was less diseased; it had lost its translucency, was partly red and Jellow; the former arising from ecchymosis; the latter from a layer of lymph on its surface. Repetatur mistura.

Imponatur emplastrum vesic. pone aures sing.

July 19th. The blisters had risen well; but, from the pain they occasioned, prevented the patient sleeping; and this morning he complained of being languid and low. The hearing continued to improve, and the humming and ticking were much fainter: the latter sometimes entirely ceased. The membraua tympani of the right ear had lost its moist, vascular, granulating surface; and was dry and smooth, rather shining, and of a flesh colour; not yet presenting the appearance of membrane, being obviously thickened, and its colour arising from the red vessels traversing it. Corresponding with the projection of the handle of the malleus were the remains of granulating papillæ. The left membrana tympani was smooth and dry, but less shining, and of a darker colour than natural; which was produced by red vessels traversing it, and which can be distinctly perceived.

July 22nd. IIe continued to improve; his hearing had increased, and the tinnitus diminished. The membrana tympani of the right ear presented much the same appearance as at the last visit, but had lost the red central projection; that of the left, as far as the light would admit of its being seen, appeared to have regained nearly its natural appearance.

July 26 th. The deafness, though not entirely gone, was not perceptible in conversation; and the tinnitus had diminished to a slight buzzing. The membrana tympani of the right ear had lost its flesh colour, but had not recovered its translucency, having an opaque, dirty, yellowish white appearance. On parts of its surface, some remains of dry blood were visible. The projection caused by the short process of the malleus could be seen, but not the handle of this bone, owing to the thickening of the membrane. A vascular swelling had made its appearance on one part of the circumference of the left membrana tympani; and, on touching this swelling with the probe, great sensibility was evinced. On conversing with him to-day, he informed me that he has been subject to ear-ache with discharge, more frequently with the right than the left ear; and the attack which he mentioned having suffered from thirty years ago was only the first in his recollection. Notwithstanding the more frequent attacks of the right ear, he heard better with it than with the other.

Applicatur lotio zinci sulphatis.

August 11th. The lotion prescribed in the last note, mixed with an equal quantity of hot water, had been injected into each ear, night and morning; and to-day he came to thank me, considering himself quite well. He still had occasional noises in the left car, and did not hear so well with it as the other; a watch held opposite this, was but just heard at a distance of four inches, while the other ear distinguished it at a distance of forty inches. On closing the mouth and nostrils, and expiring strongly, no sensation was produced on the left side; while the air passing through the Eustachian tube, and into the tympanum of the right, caused some pain. The day was too dull to admit of a satisfactory examination of the membranæ; but as far as could be seen thes appeared nearly healthy.

REXARKS. The inflammatory appearances presented by the

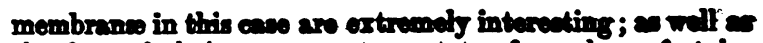
the fact of their recovery to a stato of nearly perfeot integrity, notwithstanding the serere character of the inflammation, and the repeated attacts from which the pationt had previously suffered. It is deserving of remart that the hearing was better in the right ear than in the left, notwithstanding the more frequent attacks to which it had been subject, and the more diseased appearance of its membrana tympani: this was probably owing to the patent condition of the Eustachian tube of the side, while that of the opposite was either temporarily or permanently closed.

Mr. Wilde, in his excellent work on Aural Surgery, is the only writer I have met with who makes mention of the peculiar appearance sometimes presented by the membrana tympani, of which the right ear in this patient affords an example. "In some instances," observes Mr. Wilde, "the whole surface (of the membrane) was not only of a deep red, but also granular, like that of a ripe raspberry, or, the appearance so frequently presented on the inside of the upper eyelid,-such were cases of long continued otorrhces." The case just reported would show that there is no necessary connection between the condition of the membrana tympani just described, and a long continued otorrhoea.

[To be continued.]

9, New Burlington Strcet.

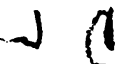

\section{ON THE ORIGIN AND TREATMENT OF CHRONIC DISEASES OF THE SKIN.}

By THOMAS HUNT, F.R.C.S., Surgeon to the Western Dispensary for Diseases of the Skin.

No. 111 .

HAVING made some observations on the general principles of treatment, and having alluded to the constitutional origin and complications of cutaneous diseases, I proceed to exemplify by cases, selected chiefly from dispensary practice, shewing how these principles are applicable to the different orders and genera in which these diseases were classed by Drs. Willan and Bateman. In so doing, I shall not dwell minutely on the anatomy of the skin, as my object is wholly practical; and the practice, in order to be successful, must be directed rather to the internal or general cachexia manifested by the eruption, than to the particular structure involved in the disease.

$$
\text { ORDER I.-PIMPLES (PAPULE). }
$$

When a pimple, or cluster of pimples, occurs, containing no fluid, shewing no tendency to suppuration, and terminating in no result, except a particle of scurf at the apex of the pimple, the disease belongs to the order papulae.

The Dis thosis ought, therefore, to be simple and easy. But cases occur in which, if some of the pimples contain no fluid, others contain pus or serous matter; and in the more severe forms of lichen, fluid enough is discharged to produce a crust which conceals the original papulæ, and the case may be mistaken for cczema or psoriasis. Thus papulous diseases are easily mistaken for vesicular, tubercular, or even pustular and squamous affections. Again, in severe prurigo, the pimples being of the colour of the skin, and the apex being generally flat or truncated, nothing appears but marks of the patient's nails and little black spots, which are the dried blood discharged by the wounding of the pimples. Moreover, lichen is often complicated with urticaria, which altogether masks the original form, and indeed presents a new and important indication in the treatment. Lichen is also very liable to be mistaken for scabies.

The Progyosis is as various as the cases presented. Strophulus, the infant form of lichen, soon gets well, with or without appropriate treatment. Lichen, when it occurs in the face, is extremely difficult of treatment, especially in middle aged females, who are the most frequent victims. 


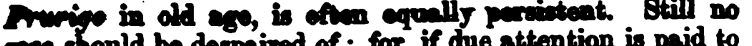
ace ahould bo despeired of ; for, if due attention is paid to lieved, and in most cases permanently cured.

Treatment of papulous diseases. Strophulus, or redgum, occurs only in infants, and is always sympathetic of some more important lesion, which in young infants genemally proves to be gastric irritation; in infants more adwanced, irritation of the general system from dentition. In the former, aperients and antacids are required, with some change in the diet; in the latter, free lancing of the gums, aperients, and the warm bath: and this applies to all kinds of eruptions, slight or severe, occurring at the period of dentition. Lichen may be acute or chronic, or both, or neither; it may originate in external causes of irritation, or it may be sympathetic of some functional disorder; or, in its chronic form, in every degree of severity, it may be caused by some defect of elimination, or other vicious condition of the circulating fluids. Its treatment must therefore be varied according to circumstances. The following cases illustrate this.

CAsE I. Lichen Simplex. P. W., aged 33 years, a single woman, of costive habit, who had recently been subject to some degree of sickness and palpitation at the heart, but otherwise healthy, had been troubled for a few weeks with an eruption of pimples covering more or less the whole body, which annoyed her very much by its constant itching She was cleanly in her person, and no external cause for the eruption could be pointed out. The eruption yielded entirely, in a month, to the purgative effect of five grains of blue pill and the same quantity of pilula colocynthidis composita, taken every alternate night.

CASE II. Lichen in a gouty subject. T. A., aged 63 years, subject to gout, somewhat deaf, with a discharge from the meatus externus, had been troubled for four months with an cruption of red pimples in the face and scalp. The disease yielded in a few weeks to the persevering use of colchicum with occasional purgatives.

CASE IIr. Chronic Lichen. J. T., aged 39 years, a healthy subject, but of costive habit, had been subject to an eruption of pimples about the neck, legs, and other parts, for more than nine ycars, for which little relief had been obtained by any treatment hitherto prescribed. A dose of purgative pills every other night, and ten minims of the fiquor arsenici chloridi taken three times a day for exactly three months, completely dissipated the eruption, which remained well for ten months, when it returned in a slight degree, and yielded in less than six weeks to exactly similar treatment. No external application was used except the tepid bath.

C.ASE 1v. Lichen Agrius. S. G., aged 70 years, in good health, but remarkably deficient in perspiration of late, had suffered for two months with a severe attack of lichen agrius in the loins and hips chiefly. The skin was exceedingly irritable, and covered with crusts and fissures. The patches of crust were surrounded with red pimples. He was treated by purgatives and the chloride of arsenic, to which the disease yielded, but not until he had been under treatment for four months. During this period, he had three distinct attacks of gout, under which the arsenic was not intermitted, but a grain of the extract of colchicum was taken every night. In the third month, he had an attack of herpes zoster. This patient found great relief from the glycerine lotion.

Case v. Lichen Simplex. W. M., aged 31 years, an indoor servant, in excellent health, but somewhat plethoric habit, had suffered for twenty years from an eruption of papulæ in the fingers of both hands, which annoyed him, not less by its suspicious appearance, than by its constant itching. His diet was ordered to be reduced; and he took the compound rhubarb pill and the chloride of arsenic for exactly eight weeks, when he was discharged perfectly cured.

Case vi. Lichen Crticatus. M. P., aged 18 years, a girl of impaired health, had suffered from frequent eruptions of wheals and papula in the face for three years. Although the functions were regularly performed, sho enfered s good deal from headache and pain under the left breact. She often complained of giddiness, throbbing in the forehead, and aching in the eye-balls. The pulse was feeble, and the tongue slightly costed. A great variety of purgatives were administered, together with a course of Fowler's solution of arsonic. She was dry cupped on the back occasionally, and a tepid bath was ordered once a week. She recovered in six weeks. Three months afterwards, she had a slight relapse, with headache, which yielded to similar treatment. It is possible that the arsenic had little to do with the cure.

It often happens that young women are troubled with lichen urticatus occasionally for years together, which yields at length rather to some change in the system than to treatment. It is very apt to recur in the spring and summer; and this I have observed more frequently in lichen than in any other kind of eruption.

These cases will serve to illustrate the important fact, that no rule can be laid down for the treatment of lichen, a disease which is so closely connected with more general ailments, that it will seldom yield until these are corrected. If I were disposed to generalise at all, I should say that lichen scldom requires tonics, except when associated with anæmic amenorrhœa, a rare occurrence. It is a form of eruption which more rarely attends asthenic than sthenic and plethoric states of the system. Gout, dyspepsia, visceral congestion, and imperfect elimination, are its more frequent complications.

Prurigo consists of an eruption of pimples of the colour of the surrounding sking with flattened summits, rarely terminating in desquamation or scurf. It may affect one locality only, as the scrotum, the anus, or the vulva; or it may be general.

Disanosis. It is distinguished from lichen by its colourless and flattened papula, which are frequently discernible only by their black summits, the result of scratching: and from scabies, by the intolerable character of the irritation, which is compared to the stings of iusects, affects the subcutaneous tissue as well as the skin, and is rather aggravated than relieved by scratching. Prurigo in its worst forms is the most terrible of all diseases. It always drives the patient out of society, and frequently deprives him in some degree of reason. Ho generally thinks and talks of suicide, and sometimes commits it. Occusionally there are no papules to be seen, but the irritation is intolerable. The disease is then called pruritus; but it has the systemic character of prurigo, and requires similar treatment.

The Progrosis should be regarded as doubtful. For although it will generally yield to treatment, there are cases which prove unmanageable.

Treatuent. When prurigo in any of its local forms, arises from local causes, such as ascarides in the rectum, ovarian irritation, or leucorrhoea, it will yield to treatment directed to its origin; but when there is no local cause to be discovered, although the disease may be locally manifested, and also when the disease is general-in both these cases, cases in which no remedy was to be found in the whole storchouse of medical literature a few years ago, I have found arsenic so frequently successful, that, although there may be circumstances which may prevent its full efficiency. I cannot but regard it as exercising in all cases, when duly administered, some valuable control over this fearful malady. I have already published four cases, in which the patients were rescued from intolerable wisery by this medicine. Two of them (one prurige scroti, the other prurigo podicis) perfectly recovered without any relapse; the third, a case of general prurigo formicans, suffered no relapse for three or four years; and of the fourth (prurigo pudendi muliebris), I bave heard $\mathbf{n}$ account, but great relief was obtained at the time the patient was under my care. My subsequent experience, which has extended over about seventy or eighty cases of this disease, has fully confirmed my published opinion of the value of arsenic. The following cases are taken indiscriminately from my dispensary case-book. 
O10 I. Prurige of the trunk and genitals.: 1 married woman, aged 36 jears, without family, who mado no complaint of her general health, except that she was costive, applied, November 11th 1851, complaining of intolerable irritation over the trunk of the body, which was covered with black specks. The vulva and anterior portion of the vagina Tere most troublesome. She describes the itching as like finely pointed needles or stings running into her skin. She had suffered from this horrible disease twenty-two years, and believed it to be hereditary, as her mother complained of a similar ailment. She was treated with arsenic for one month; at the end of which period the disease was, to use her own expression, "worse than ever", although the bowels had been attended to. Warm baths were now prescribed; and as her conjunctivæ were affected, the dose of arsenic was reduced, and a few drops of tincture of opium added to each dose. Under this she rapidly improved; and by the 2nd of January, 1852, was discharged cured. The disease returned on the trunk only, about three months afterwards, "like something crawling", and it yielded rapidly to the chloride of arsenic. I have seen nothing of the patient for nearly three years. There were symptoms of hysterical irritation about this patient, but whether as a result or as a cause of this disease, I could not ascertain.

CaSE II. Prurigo. A widow, aged 40 years, subject to "rheumatic gout", applied for relief from a distressing eruption of flattened papula of the colour of the skin, affecting the whole trunk of the body. It had existed twelve months. She had not menstruated for two years. She had had no sleep for a long time; and her body was completeiy covered with scarifications in all directions, inflicted by her nails. She imagined that insects were "breeding and crawling all over her"; but it was not so: in fact, her sufferings had affected her intellect. She had the air and manner of a maniac. Arsenic, Plummer's pill, and warm baths, were prescribed; but, after a week's trial, finding no relief, shc absented herself in despair.

$\mathrm{C}_{\triangle \mathrm{SE}}$ IIr. Pruritus. A man, aged 66 years, had been troubled with intolerable itching all over the body for about twelve months, which affected the health, by depriving him of rest at night. He was a person of cleanly habits, and had no eruption. He was cured in six wecks by Fowler's solution of arsenic. Warm baths were prescribed, but not used. The irritation returned when the arsenic was discontinued, and was a second time relieved by it.

CASE IV. Pruritus. A respectable widow, aged 55 years, in good health, but of costive habit, had suffered for eight years from a general irritation of the whole surface of the body and the mucous lining of the vagina. It was aggravated by warmth, and she had slcepless nights. A variety of remedies were tried for three months without any relief being obtained, when the chloride of arsenic was administered in the usual doses, which cured her in seventeen days.

Case v. Prurigo Formicans. A widow, aged 40 years, had suffered from prurigo, affecting the whole surface in a severe form, for two years. When she applied at the dispensary, she complained of short breath, scanty urine, and slight cedema of the feet and legs. Pills composed of calomel and compound colocynth pill, every other night, and a diuretic mixture three times a day, consisting of acetate of potash, squills, and spiritus ætheris nitrici, cured the oedema and shortness of breath in a fortnight; and with these diseases the prurigo vanished.

This case establistes the principle, that cutaneous diseases will often yield to treatment directed to the general health, when it is defective. Where no such complication exists, I have found nearly as much success with arsenic in pruriginous disease as in other forms of cutancous disease. I should not omit to mention that prurigo is occasionally sympathetic of fulness of the vascular system, as well as of gout, dyspepsia, dropsy, or jaundice, so that it may require in one case, blood-letting; in another, colchicum; in a third, stomachics and aperients; in a fourth, diuretics; and in a ffth, wlomel. . There is no divens which requins more investigation. It is often complicated with boils and carbuncles.

In taking my leave of the order papulo, it may be well to observe that an eruption of pimples rarely indicates a low and asthenic condition of the system; more frequently, indeed, it shows a necessity of depletion. It is, in almost all cases, associated, more or less, with constipation of the bowels; and I believe little success would attend any hind of treatment in papulous affections without the repeated and even frequent exhibition of purgatives. That these medicines alone are, howerer, generally insufficient, I have had ample proof. The subjects of papulous diseases are commonly persons of a dry habit of body. The perspiration and urine, as well as the alvine and uterine secretions, are spare and scanty.

An important distinction should be made between papulous disease arising from constitutional causes, and those arising from the irritation of pediculi, which, though generally associated with extreme uncleanliness, certainly do sometimes infest the skin of persons of advanced age and lanuid circulation, in spite of every care. If mercurial applications should fail to destroy them, a general inunction of oil or lard would probably succeed. Meanwhile, the health should be invigorated by stimulants and tonics. All parasites thrive best on weak aud debilitated subjects.

[To be continued.]

Alfred Place, Bedford Square.

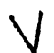

DISLOCATION OF THE TIBIA BACKWARDS, WITH FRACTURE OF THE PATELLA.*

By T. OGIER WARD, M.D.

ON February 14th, 1853, Mrs. G., aged 40 years, returning home in the frost, slipped and fell, with her right knee upon the curb-stone, striking it with such violence as to fracture the patella, and dislocate the tibia backwards. As she lived near me, I saw her very soon after the accident, and found her in great pain, with the leg extended, the front of the thigh and leg forming two parallel lines, but with the knee forming a wide interval or slip between them. The ligamentum patellæ was very tense, and the patella was broken across, a considerable interval being perceptible between the broken portions. The head of the tibia was easily felt in the ham, and the condyles of the femur resting upon it, as there was no great amount of swelling.

As the nature of the case was very evident, I immediatcly tried to reduce the limb by forcible extension by the foot; but finding this of no use, I knelt down on one knee, and placing the other under the patient's thigh, I pressed down and flexed the leg, at the same time that her husband extended the foot, and in a very short time, after two or three effiorts, we succeeded in bending the knee, and the reduction was effected, but was unattended by any snap, or jerk, or sudden change of form in the limb. The limb was then kept extended by splints and a roller, and the fractured portions of the patella were brought together. A few leeches, with fomentations, were applied, and she was purged, and took antimonial salines for four days to reduce the inflammation; after which time, confinement to her bed was all that was required to effect a cure. In eight weeks after the accident, she quitted her bed with stiff knee; but she is now able to bend it about 35 degrees; and she walks considerable distances with the help of stick; but she suffers from rheumatic pains in that joint, as she did before the accident. The two portions of the patella are united within half an inch.

Kensington, London, January 10th, 1855.

- This is the case referred to by Dr. Ward at the meeting of the Iloye Medical and Chirurgical Society on the 12th December. [Vide p. 13.] 